KEMIJA U NASTAVI

Uređuje: Nenad Raos

https://doi.org/10.15255/KUI.2019.034

\title{
Kemijski (silikatni) vrt, jedan pokus za obrazovanje u STEM području
}

\author{
M. Čalogović*
}

ProGEO-Hrvatska, Horvatovac 102a, 10000 Zagreb

\begin{abstract}
Sažetak
Vizualizacija kemijskih procesa iznimno je važna i korisna u edukaciji kemije. Jedan od takvih pokusa je i kemijski vrt koji nastaje dodavanjem topljive soli metala u otopinu natrijeva silikata ili nekog drugog aniona s kojim metalni ion daje koloidni gel koji stvara polupropusnu membranu. Rastom kemijskog vrta nastaju cjevčice različitih veličina i oblika koje podsjećaju na stabalca i biljke u vrtu. U članku se opisuje izrada kemijskog vrta upotrebom lako dostupnih kemikalija. Taj pokus na jednostavan način predočuje precipitaciju povezanu s osmozom i izvrsno je edukativno sredstvo.
\end{abstract}

Ključne riječi

STEM, pokusi, osmoza, silikati, nastava kemije

\section{Uvod}

Sredinom 20. stoljeća u edukativnim kompletima za upoznavanje djece s kemijom nalazio se i pokus nazvan "kemijski vrt" (ponekad nazivan "kristalni vrt", pa i "čarobni vrt" npr. u Kozmosovom kompletu "Magisches Garten"). lako se ti kompleti više ne mogu nabaviti, nije nam uskraćena mogućnost eksperimentiranja jer takav "vrt" možemo uz malo truda i ulaganja napraviti i sami, a možemo potaknuti i učenike da sudjeluju u njegovu stvaranju. Potrebno je samo malo dobre volje, nekoliko lako dostupnih kemikalija i mali akvarij ili slična staklena posuda. To je pokus u kojem nastaju strukture slične biljkama (gljivama, mahovini...) kada se doda topljiva sol metala, često kao kristalić ("sjeme") u vodenu otopinu koja sadrži anione, a najčešće otopinu natrijeva silikata (takozvanog vodenog stakla) pa se još naziva i "silikatni vrt" (slika 1).

Taj je pokus u prošlom stoljeću zbog nastanka (rasta) struktura koje nalikuju živim organizmima pobudio interes istraživača koji su se bavili problemom postanka života. ${ }^{1}$ I danas, nekoliko stoljeća nakon što je prvi put opisano opažanje "metalnih stabalca" (među prvima ih je opisao Glauber $^{* *}$ 1646. g.), kemijski vrt nije u potpunosti objašnjen. ${ }^{2}$ Premda se fenomen rasta kemijskog vrta istražuje već dulje vrijeme, još uvijek ne znamo koje sve fizičke i

\footnotetext{
* Marina Čalogović

e-pošta: mcalogovic06@gmail.com

** Johann Rudolph Glauber (1604. - 1670.) bio je njemačko-nizozemski apotekar i kemičar poznat po otkriću medicinskog djelovanja i načina proizvodnje natrijeva sulfata (nazvanog po njemu Glauberova sol). Godine 1651. izdana je njegova knjiga Furni Novi Philosophici gdje je među ostalim pokusima opisao i kemijski vrt.
}

kemijske varijabile uvjetuju morfologiju tih mikrocjevčica, a nije ni posve objašnjen mehanizam njihove geneze. Zato neki metodičari smatraju da taj pokus nije primjeren za podučavanje, ali ja se priklanjam mišljenju da se iz tog pokusa

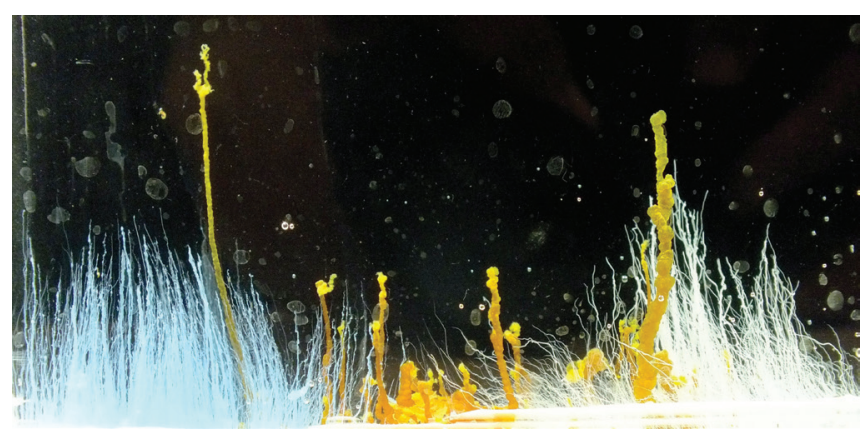

Slika 1 - Silikatni vrt napravljen u vodenom staklu razrijeđenom destiliranom vodom u omjeru 1:4. Plave niti nastale su od kristalića bakrova(II) sulfata pentahidrata (modre galice). Narančaste tvorevine nastale su od kristalića željezova(III) klorida ("feriklorida"). Blijedo zelene niti potječu od željezova(II) sulfata heptahidrata (zelene galice). Snimljeno nakon približno 6 minuta od stavljanja kristalića u otopinu. Najviša cjevčica duga je $6 \mathrm{~cm}$.

Fig. 1 - Silicate garden made in water glass diluted with distilled water in ratio $1: 4$. Blue tubes are formed from copper(II) sulphate pentahydrate (blue vitriol) crystals. Orange formations are formed from iron(III) chloride (ferric chloride) crystals. Pale green tubes are formed from iron(II) sulphate heptahydrate (green vitriol) crystals. Photograph was taken 6 minutes after adding crystals to a solution. The highest tube is $6 \mathrm{~cm}$ long. 
može dosta naučiti, prije svega o topljivosti, precipitaciji i kristalizaciji koja je opet povezana s dinamikom fluida te osmozom, i da mu je mjesto u nastavi.

Kemijski vrt nastaje precipitacijom metalnog kationa iz dodane soli i aniona kao što su aluminati, borati, karbonati, kromati, fosfati i sl. Umjesto kristala može se dodati i otopina soli metala, pa tada dolazi do reakcije na granici dviju otopina, a opisan je i pokus u kojem su upotrijebljeni komadići cinka i aluminija. ${ }^{3}$ Bez obzira na njihovu raznolikost, zajedničko svojstvo im je precipitacija polupropusne membrane kroz koju se odvija osmoza. Takve je membrane prvi proučavao Traube* početkom 19. stoljeća, a nakon njega ih je Pfeffer ${ }^{* *}$ upotrebljavao $u$ istraživanjima procesa osmoze. Ta su istraživanja navela Jacobusa van't Hoffa ${ }^{* * *}$ da objasni osmozu te da otkrije zakon osmotskog tlaka 1877. godine. (1901. je dobio Nobelovu nagradu za to otkriće, što je bila prva Nobelova nagrada iz kemije).

\section{Opis procesa nastanka kemijskog vrta}

Premda se za izradu kemijskog vrta najčešće upotrebljava vodeno staklo, kemija i ponašanje natrijeva silikata $\left(\mathrm{Na}_{2} \mathrm{SiO}_{3}\right.$ i malo $\left.\mathrm{Na}_{2} \mathrm{Si}_{2} \mathrm{O}_{8}\right)$ u otopini je dosta kompleksno zbog sklonosti silikata da polimeriziraju. Otopina natrijeva silikata djeluje jako lužnato zbog hidrolize a može se

\footnotetext{
Moritz Traube (1826. - 1894.) bio je njemački kemičar i bavio se kemijskim, biokemijskim, medicinskim, fiziološkim i patofiziološkom problemima.

** Wilhelm Pfeffer (1845. - 1920.) bio je njemački botaničar i biljni fizio$\log$.

*** Jacobus van't Hoff (1852. - 1911.) bio je nizozemski kemičar koji se bavio fizikalnom i organskom kemijom. Istraživao je kinetiku kemijskih procesa, kemijsku ravnotežu, osmotski tlak i kristalografiju.
}

pripremiti otapanjem silika-gela u natrijevoj lužini uz zagrijavanje.

Dodatkom kristala topljive soli nekog metala u vodeno staklo dolazi do nastanka hidratiziranog metalnog silikata koji se taloži kao koloidni gel oko kristala. Gel se ponaša kao polupropusna membrana kroz koju voda i hidroksidni ioni (u suvišku) prolaze zbog osmotskog tlaka. U tom procesu kristal soli se dalje otapa, a membrana koja ga okružuje se rasteže dok ne pukne te izbaci mlaz otopine u okolnu tekućinu. Na svakom mjestu gdje membrana pukne nastanu cjevaste niti. Pri adekvatnim uvjetima niti mogu narasti i do nekoliko centimetara u duljinu (slika 1) čime nastaje kemijski vrt (slika 2).

Većina metala, osim alkalijskih čiji su silikati dobro topljivi, uzrokuju rast takvih niti. Različite soli metala daju različitu boju kemijskom vrtu. Bakrov(II) sulfat pentahidrat (modra galica) daje plave niti, soli nikla stvaraju svjetlozelene, a kalcijev klorid daje bijele niti. ${ }^{4}$ Kod nekih soli boja niti se razlikuje od boje soli, pa tako žuti željezov(III) klorid stvara crveno-smeđe niti, a željezov(II) sulfat heptahidrat (zelena galica, $\mathrm{FeSO}_{4} \cdot 7 \mathrm{H}_{2} \mathrm{O}$ ) bijele koje potom pozelene. ${ }^{5}$ Može se uočiti i da morfologija cjevčica ovisi o soli metala tako da su neke soli stvorile tanke, a neke debele i grudaste niti.

Često se za kemijski vrt upotrebljavaju kobaltove soli jer daju vrlo lijepe oblike ružičastoljubičaste boje, ali ja sam upotrebljavala modru galicu, zelenu galicu i željezov(III) klorid (prodaje se u trgovinama s elektroničkim priborom pod trgovačkim nazivom "feriklorid") koji se mogu jednostavnije nabaviti i manje su štetni. Također se može upotrebljavati i bezvodni kalcijev klorid koji se prodaje u trgovinama boja i lakova kao sušilo. Neke od tih soli mogu se pripremiti i u laboratoriju: modra galica dobiva se otapanjem bakra u sumpornoj kiselini, a zelena galica otapanjem željeza u sumpornoj kiselini te kristalizacijom iz otopine.
A

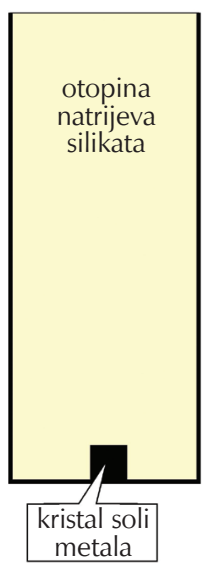

B

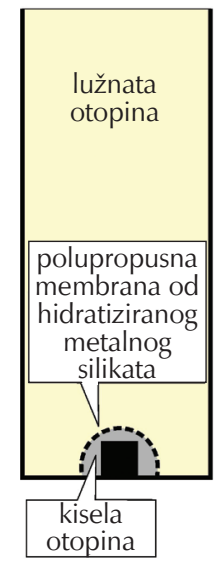

C

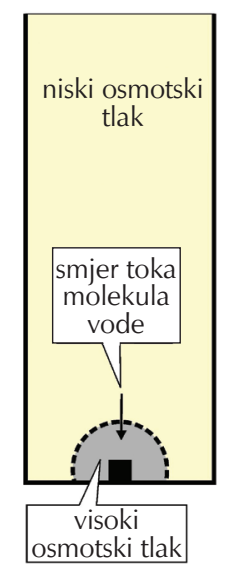

$\mathrm{D}$

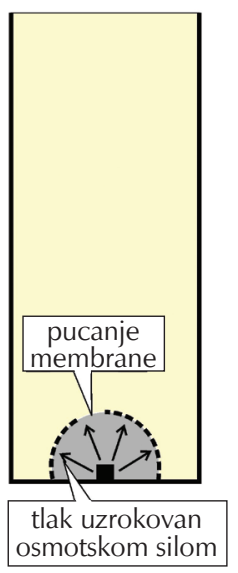

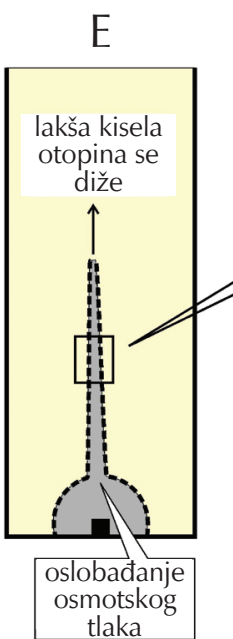

siojbogat sloj bogat bogat

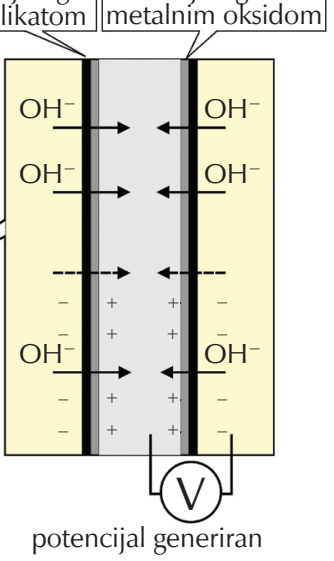

gradijentima $\mathrm{pH} /$ iona

Slika 2 - Princip rasta kemijskog vrta: A) situacija na početku reakcije, B) nastanak membrane između kisele i lužnate otopine, C) membrana se širi jer je osmotski tlak unutar membrane veći nego izvan, D) membrana puca i E) nastanak cjevčica. Prema Cartwright i sur., 2002. (ref. 6, prilagođeno)

Fig. 2 - Outline of chemical garden growth: A) situation at the start of the reaction, B) membrane forms between acidic and basic solutions, C) membrane expands because the osmotic pressure is higher within it than outside of it, D) membrane ruptures, and E) a tube forms. From Cartwright et al., 2002 (Ref. 6, modified). 


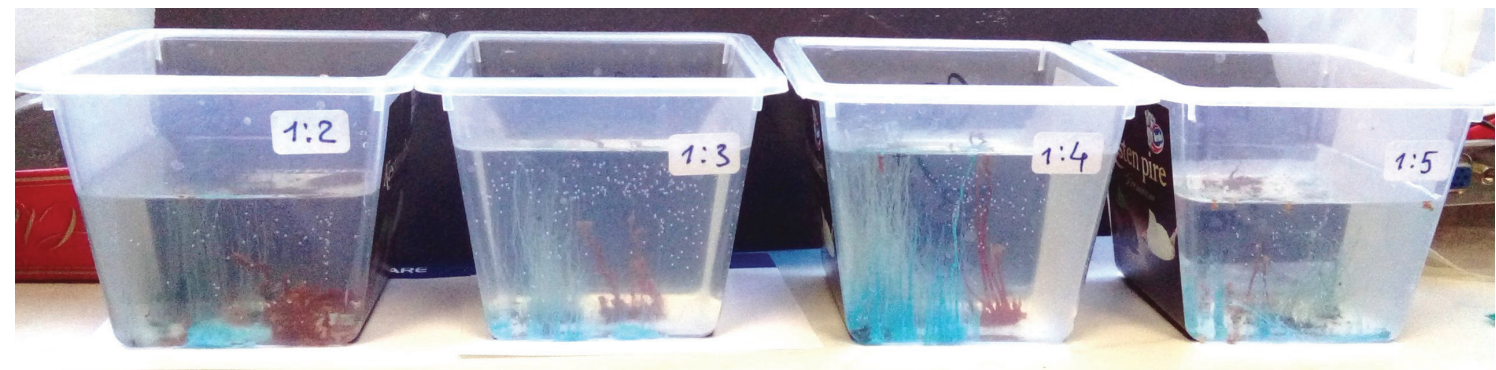

Slika 3 - Testiranje rasta kemijskog vrta u vodenom staklu razrijeđenom destiliranom vodom u različitim omjerima Fig. 3 - Testing chemical garden growth in water glass diluted with distilled water in various ratios

\section{Utjecaj koncentracije vodenog stakla na rast kemijskog vrta}

Postoji raspon kemijskih kombinacija koje pogoduju rastu kemijskog vrta. To ukazuje da njegov rast nije toliko ovisan o koncentraciji koliko o procesu precipitacije i fizičkim svojstvima precipitata. Stoga nema jedinstvenog recepta za sve soli metala. ${ }^{6}$

Upotrebljavala sam vodeno staklo (proizvođač je Kemoplastika iz Zagreba), koje se može nabaviti u prodavaonicama boja i lakova te odlučila isprobati različite omjere razrjeđenja da utvrdim koji je najpogodniji za raspoložive soli. U četiri posudice (slika 3) stavljeno je vodeno staklo razrijeđeno destiliranom vodom u omjerima: 1) $1: 2,2$ ) $1: 3$, 3) $1: 4$ i 4) $1: 5$. Pokazalo se da je za neke soli u koncentriranijoj otopini kemijski vrt brže rastao, a za druge soli je pri istoj koncentraciji samo bubrio i slabo rastao (nastao je gel oko kristala, no nisu nastale niti). Umjerene koncentracije pokazale su se najpogodnijima jer su tada sve tri odabrane soli stvorile niti. S druge strane, premala koncentracija ponovno je dala samo gel.

Pretpostavlja se da u koncentriranijoj otopini membrana puca teže pa niti slabo rastu, a kod razrijeđene otopine membrana postaje plastična i ponovno ne puca lako, nego se samo širi bez pucanja.

Brzina rasta cjevčica ovisi o brzini protoka kroz osmotsku pumpu koja potiče razliku osmotskog tlaka preko polupropusne membrane između unutarnje i vanjske otopine i o brzini otapanja kristala te samoj topljivosti soli metala.

Treba spomenuti da su niti u kemijskom vrtu krhke, tako da dok raste, a i kasnije ako ga se želi sačuvati, posudu s kemijskim vrtom treba držati na mirnom mjestu.

\section{Veza kemijskog vrta i postanka života}

Kada vidimo kako kemijski vrt raste, postavlja se pitanje jesu li narasle strukture (cjevčice) žive? Kako razlikovati rast kristala od rasta živog bića? Rast je samo jedno od svojstva živog svijeta, ali i neživoga (nije specifičan), a teško je definirati i sam život. ${ }^{7}$ Sjetimo se samo siga u špiljama - i one rastu.

Strukture slične kemijskom vrtu koje sadrže polupropusnu membranu mogu se naći u različitim okolišima u prirodi. Najviše su istraživani hidrotermalni izvori na dnu oceana jer postoji moguća sličnost s okolišem gdje je nastao prvi Život na Zemlji. ${ }^{8}$ Život se može opisati kao visokoorganizirani sustav koji je nastao iz samoorganizirane kemije, a ovisi o kemijskoj i elektrokemijskoj neravnoteži na sličan način kao što ovisi i kemijski vrt.

Cjevčice u kemijskom vrtu zapravo su membrane nastale zbog kemijske, prije svega pH-neravnoteže između dviju otopina različita sastava, pa njihovo svojstvo samoorganizacije ustraje sve dok postoji neravnoteža.

\section{Zaključak}

Kemijski vrt je prije svega jednostavan pokus kojim se vizualizira niz kemijskih procesa, ali koji može biti inspirativan i za dublje proučavanje njegove geneze, dinamike rasta membrana i promišljanja o njihovoj analogiji sa živim sustavima te mogućoj ulozi u postanku života.

Kemijski vrt je pogodan za izvođenje u učionici jer se može napraviti u bilo kojem mjerilu (od epruvete do velikog akvarija). Ako se kemijski vrt izvodi u plitkoj posudi, niti mogu narasti do površine te se počinju njome širiti stvarajući strukture slične gljivama i lopočima. Da bismo ga sačuvali, treba ga hermetički zatvoriti kako vodeno staklo ne bi reagiralo $\mathrm{s}$ atmosferskim $\mathrm{CO}_{2}$, uslijed čega se otopina zamuti. Tako hermetički zatvoren, kemijski vrt se može čuvati godinama.

Kao zadatak za eksperimentalno učenje i podučavanje kemije, kemijski vrt je pokus koji treba imati svoje mjesto u STEM-orijentiranom kurikulumu kemije. 


\section{Literatura \\ References}

1. N. Raos, The Cookbook of Life - New Theories on the Origin of Life, HDKI/Kemija u industriji, Zagreb, 2018., str. 240.

2. L. M. Barge, S. S. S. Cardoso, J. H. E. Cartwright, G. J. T. Coper, L. Cronin, A. De wit, I. J. Doloboff, B. Escribano, R. E. Goldstein, F. Haudin, D. E. H. Jones, A. L. Mackay, J. Maselko, J. J. Pagano, J. Pantaleone, M. j. Russell, C. I. Sainz-Díaz, O. Steinbock, D. A. Stone, Y. Tanimoto, N. L. Thomas, From chemical gardens to chemobrionics, Chem. Rev. 115 (2015) 86528703, doi: https://doi.org/10.1021/acs.chemrev.5b00014.

3. L. A. Hausman, Chemical Flower Bed. Popular Mechanics 48/5 (1927) 844-845.

4. J. H. E. Cartwright, B. Escribano, C. I. Sainz-Díaz, Chemical-garden formation, morphology, and composition. I. Ef- fect of the nature of the cations, Langmuir 27 (2011) 32863293, doi: https://doi.org/10.1021/la104192y.

5. F. Glaab, J. Rieder, J. García-Ruiz, W. Kunz, M. Kellermeier, Diffusion and precipitation processes in iron-based silica gardens, Phys. Chem. Chem. Phys. 18 (2016) 24850-24858, doi: https://doi.org/10.1039/c6cp02107g.

6. J. H. E. Cartwright, J. M. García-Ruiz, M. L. Novella, F. Otálora, Formation of chemical gardens, J. Coll. Interf. Sci. 256 (2002) 351-359, doi: https://doi.org/10.1006/jcis.2002.8620.

7. P. L. Luisi, About various definitions of life, Orig. Life Evol. Biosph. 28 (1998) 613-622, doi: https://doi. org/10.1023/A:1006517315105.

8. M. J. Russell, A. J. Hall, The emergence of life from iron monosulphide bubbles at a submarine hydrothermal redox and pH front, J. Geol. Soc. (London) 154 (1997) 377-402, doi: https://doi.org/10.1144/gsjgs.154.3.0377.

\section{SUMMARY}

Chemical (Silicate) Garden, One Experiment for Education in STEM Field

\section{Marina Čalogović}

Visualization of chemical processes is of primary importance in chemistry education. One of such experiments is the chemical garden, which is formed by addition of soluble metal salts in a solution of sodium silicate, or some other anion that forms a colloid gel with a metal ion. Gel forms tubular semi-permeable membranes, which morphologically resemble garden plants. This paper describes preparation of a chemical garden with easily obtainable chemicals. This simple experiment visualizes osmosis-related precipitation and is a very convenient teaching tool.

\section{Keywords}

STEM, experiments, osmosis, silicates, chemical education

ProGEO-Croatia

Horvatovac 102 a

10000 Zagreb, Croatia
Professional paper

Received July 29, 2019

Accepted August 3, 2019 